\title{
DISTRIBUTIONS OF HYDRODYNAMIC PRESSURE IN THE GAP OF SLIDE JOURNAL BEARING LUBRICATED WITH FERRO-OIL
}

\author{
Marcin Fryez \\ Gdynia Maritime University \\ Faculty of Marine Engineering \\ Morska Street 83, 81-225 Gdynia, Poland \\ tel.: +4858 6901335, fax: +48586901399 \\ e-mail:m.frycz@wm.umg.edu.pl
}

\begin{abstract}
This research work is part of a broader comprehensive issue, which is the analysis of flow and operating parameters of journal slide bearings lubricated with ferro-oil. In this article, the author presents only the main assumptions and essential transformations of the analytical and numerical model for determining the pressure distributions in the gap of a slide journal bearing lubricated with ferro-oil. It is cardinal that the rheological and magnetic values of ferro-oil parameters adopted in numerical calculations are based on the results of actual values obtained in the author's earlier research work. There are presented the pressure distributions by abovementioned method in the article for cases of bearings lubricated with ferro-oils with different concentration of magnetic particles. The obtained results are shown in the form of a set of four complementary characteristics of the dimensionless pressure distributions. First and main of them are the calculations for classical Newtonian lubrication but they take into account the influence of the magnetic field on the distributions. The next of the presented characteristics are so-called "corrections" of pressure distribution values, taking into account as follows: effects of changes in ferro-oil viscosity related to temperature changes, impacts of ferro-oil viscosity changes related to pressure changes and the effect of non-oil properties of the lubricant. The article includes a qualitative and quantitative analysis of the obtained results as well as observations and conclusions are presented in it.
\end{abstract}

Keywords: temperature distribution, journal slide bearings, ferro-oil

\section{Introduction}

Knowledge of the distributions of the hydrodynamic pressure in the oil film of the slide bearing can be a valuable source of information on the conditions of its operation, in particular information on the nature of the tribological processes taking place in it. The specific physic-chemical properties of ferro-oil that distinguish it from other classical lubricants may determine the necessity to account for these properties in determining the flow and operating parameters of the bearing. It is necessary to take into account in the used analytical model both non-Newtonian properties of ferro-oil as well as the influence of the external magnetic field.

The first of them is a derivative of the modification that the base oil undergoes with the addition of both magnetically susceptible particles and surfactant. These modifiers make the ferrooil begins to exhibit, in addition to the classical viscosity of the oil depending on the pressure and temperature $[2,3]$ dependence of viscosity on shear rate [4]. These additives increase the viscosity of the ferro-oil relative to the base lubricating liquid.

In the second case, modelling of the hydrodynamic problem of lubrication of slide journal bearings with ferro-oil must take into account the influence of the external magnetic field on viscosity properties of the lubricant [5].

Obviously, proper modelling must also take into account the influence of both temperature and pressure on ferro-oil. Of these two, particularly the temperature change in the oil film results in significant changes in the viscosity value and, as a result, in the change in the lubrication gap height. The analytical and numerical model presented below for lubricating slide journal bearings 
with ferro-oil takes into account all of the listed factors and presents them in the form of a set of basic equations and their respective corrections to these equations.

\section{Analytical and numerical calculation model}

The analytical model of magnetohydrodynamic lubrication of slide journal bearings has been presented so far in several publications of the author [i.a. 6, 8, 12], therefore, due to limited volume of this article, only the key assumptions and transformations of the model closely related to the topic of the article will be presented and discussed.

The model was derived from fundamental equations, i.e. equations of momentum conservation, equations of flow continuity, equations of energy conservation as well as Maxwell's equations $[1,13,15-17]$. There was assumed a non-isothermal bearing lubrication model with a laminar and steady lubricant flow rate and an external magnetic field was adopted as stationary, transverse to the ferro-oil flow in the bearing gap [7].

The constitutive equation for ferro-oil was adopted from non-Newtonian viscoelastic model of Rivlin-Ericksen' fluid [13, 16, 17]. The dependence of the dynamic viscosity of ferro-oil on magnetic induction, temperature and pressure was taken into account $\eta=\eta(B, T, p)[2,3,8,10]$, whereas material factors $\alpha, \beta$ were assumed to be constant.

The constituent relationships between the coordinates of the stress tensor and coordinates of the shear rate tensor were substituted to the equations of motion. Non-stationary members and inertial forces in momentum equations were omitted. The next step in solving the system of equations was its equalization and estimation of the order of values of the unit members $[13,15]$.

For further analysis of the basic equations, it was assumed that the dimensionless density $\rho_{1}=1$ of the lubricant was constant and independent of both temperature and pressure.

The Reynolds boundary conditions in order to determine the hydrodynamic pressure in the ferro-oil were taken $[8,12,13]$.

Using the continuity equation and previously calculated peripheral and longitudinal components, after integrating the equation and applying appropriate boundary conditions, a velocity vector radial component and a Reynolds type equation were obtained for four cases:

a) for the first set of equations, which takes into, account the Newtonian properties and the influence of the magnetic field [8]:

$$
\frac{\partial}{\partial \phi}\left[\frac{h_{p 1}^{3}}{\eta_{1 B}}\left(\frac{\partial p_{1}^{(0)}}{\partial \phi}-M_{1}\right)\right]+\frac{1}{L_{1}^{2}} \frac{\partial}{\partial z_{1}}\left[\frac{h_{p 1}^{3}}{\eta_{1 B}}\left(\frac{\partial p_{1}^{(0)}}{\partial z_{1}}-M_{3}\right)\right]=6 \frac{\partial h_{p 1}}{\partial \phi},
$$

b) for the second set of equations, which takes into, account the influence of temperature on viscosity [8]:

$$
\begin{gathered}
\frac{\partial}{\partial \phi}\left[\frac{h_{p 1}^{3}}{\eta_{1 B}}\left(\frac{\partial p_{10}^{(1)}}{\partial \phi}\right)\right]+\frac{1}{L_{1}^{2}} \frac{\partial}{\partial z_{1}}\left[\frac{h_{p 1}^{3}}{\eta_{1 B}}\left(\frac{\partial p_{10}^{(1)}}{\partial z_{1}}\right)\right]= \\
=12\left\{\frac{\partial}{\partial \phi}\left[\left[\int_{0}^{h_{p 1}}\left(\int_{0}^{r_{1}} T_{1}^{(0)} \frac{\partial v_{1}^{(0)}}{\partial r_{1}} d r_{1}\right) d r_{1}-\int_{0}^{h_{p 1}} \frac{r_{1}}{h_{c 1}}\left(\int_{0}^{h_{p 1}} T_{1}^{(0)} \frac{\partial v_{1}^{(0)}}{\partial r_{1}} d r_{1}\right) d r_{1}\right)\right]+\right. \\
\left.+\frac{1}{L_{1}^{2}} \frac{\partial}{\partial z_{1}}\left[\int_{0}^{h_{p 1}}\left(\int_{0}^{r_{1}} T_{1}^{(0)} \frac{\partial v_{3}^{(0)}}{\partial r_{1}} d r_{1}\right) d r_{1}-\int_{0}^{h_{p 1}} \frac{r_{1}}{h_{c 1}}\left(\int_{0}^{h_{p 1}} T_{1}^{(0)} \frac{\partial v_{3}^{(0)}}{\partial r_{1}} d r_{1}\right) d r_{1}\right]\right\},
\end{gathered}
$$

c) for the third set of equations, which takes into, account the influence of pressure on viscosity [8]: 


$$
\begin{gathered}
\frac{\partial}{\partial \phi}\left[\frac{h_{p 1}^{3}}{\eta_{1 B}}\left(\frac{\partial p_{11}^{(1)}}{\partial \phi}\right)\right]+\frac{1}{L_{1}^{2}} \frac{\partial}{\partial z_{1}}\left[\frac{h_{p 1}^{3}}{\eta_{1 B}}\left(\frac{\partial p_{11}^{(1)}}{\partial z_{1}}\right)\right]= \\
=12\left\{\frac{\partial}{\partial \phi}\left[\int_{0}^{h_{p 1}} \frac{r_{1}}{h_{c 1}}\left(\int_{0}^{h_{p 1}} p_{1}^{(0)} \frac{\partial v_{1}^{(0)}}{\partial r_{1}} d r_{1}\right) d r_{1}-\int_{0}^{h_{p 1}}\left(\int_{0}^{r_{1}} p_{1}^{(0)} \frac{\partial v_{1}^{(0)}}{\partial r_{1}} d r_{1}\right) d r_{1}\right]+\right. \\
\left.+\frac{1}{L_{1}^{2}} \frac{\partial}{\partial z_{1}}\left[\int_{0}^{h_{p 1}} \frac{r_{1}}{h_{c 1}}\left(\int_{0}^{h_{p 1}} p_{1}^{(0)} \frac{\partial v_{3}^{(0)}}{\partial r_{1}} d r_{1}\right) d r_{1}-\int_{0}^{h_{p 1}}\left(\int_{0}^{r_{1}} p_{1}^{(0)} \frac{\partial v_{3}^{(0)}}{\partial r_{1}} d r_{1}\right) d r_{1}\right]\right\},
\end{gathered}
$$

d) for the fourth set of equations taking into account the effect of non-Newtonian properties [8]:

$$
\begin{gathered}
\frac{\partial}{\partial \phi}\left(\frac{h_{p 1}^{3}}{\eta_{B 1}} \frac{\partial p_{1 p}^{(1)}}{\partial \phi}\right)+\frac{1}{L_{1}^{2}} \frac{\partial}{\partial z_{1}}\left(\frac{h_{p 1}^{3}}{\eta_{B 1}} \frac{\partial p_{1 p}^{(1)}}{\partial z_{1}}\right)= \\
=12\left\{\frac{\partial}{\partial \phi}\left[\frac{1}{\eta_{B 1}}\left(\int_{0}^{h_{p 1} r_{3}} \int_{0}^{r_{2}} \int_{0}^{2} F\left(\varphi, r_{1}, z_{1}\right) d r_{1} d r_{2} d r_{3}-\frac{h_{p 1}}{2 \eta_{B 1}} \int_{0}^{h_{p 1} r_{2}} \int_{0}^{h_{p 1}} F\left(\varphi, r_{1}, z_{1}\right) d r_{1} d r_{2}\right)\right]+\right. \\
+\frac{1}{L_{1}^{2}} \frac{\partial}{\partial z_{1}}\left[\frac { 1 } { \eta _ { B 1 } } \left(\int_{0}^{h_{p 1} r_{2}} \int_{0}^{h_{3}} \int_{0}^{r_{2}} G\left(\varphi, r_{1}, z_{1}\right) d r_{1} d r_{2} d r_{3}-\frac{\left.\left.\left.\left.h_{1}, z_{1}\right) d r_{1} d r_{2}\right)\right]\right\},}{2 \eta_{B 1}} G(\right.\right.
\end{gathered}
$$

where:

$$
\begin{aligned}
& v_{1}^{(0)}\left(r_{1}, \varphi, z_{1}\right)=\frac{1}{2 \eta_{1 B}}\left(\frac{\partial p_{1}^{(0)}}{\partial \phi}-M_{1}\right)\left(r_{1}^{2}-r_{1} h_{p 1}\right)+1-\frac{r_{1}}{h_{p 1}}, \quad v_{3}^{(0)}\left(r_{1}, \varphi, z_{1}\right)=\frac{1}{2 \eta_{1 B}}\left(\frac{\partial p_{1}^{(0)}}{\partial z_{1}}-M_{3}\right)\left(r_{1}^{2}-r_{1} h_{p 1}\right), \\
& T_{1}^{(0)}\left(r_{1}, \varphi, z_{1}\right)=1+\frac{1}{2} \eta_{1 B}(1-2 s)-q_{1 c}^{(0)} h_{p 1} s-\frac{1}{2} \Omega_{1}\left(h_{p 1} s\right)^{2}-\frac{1}{6} h_{p 1}^{2}\left(\frac{\partial p_{1}^{(0)}}{\partial \varphi}-M_{1}\right) s\left(3-3 s+s^{2}\right)+ \\
& -\frac{1}{2} \eta_{1 B}\left[\left(v_{1}^{(0)}\right)^{2}+\frac{1}{L_{1}^{2}}\left(v_{3}^{(0)}\right)^{2}\right]+\frac{1}{24 \eta_{1 B}} h_{p 1}^{4}\left[\left(\frac{\partial p_{1}^{(0)}}{\partial \varphi}-M_{1}\right)^{2}+\frac{1}{L_{1}^{2}}\left(\frac{\partial p_{1}^{(0)}}{\partial z_{1}}-M_{3}\right)^{2}\right] s^{3}(s-2), \\
& M_{1}=R_{f} \chi\left[H_{1} \frac{\partial H_{1}}{\partial \varphi}+\frac{1}{L_{1}} H_{3} \frac{\partial H_{1}}{\partial z_{1}}\right], \quad M_{3}=R_{f} L_{1} \chi\left(H_{1} \frac{\partial H_{3}}{\partial \varphi}+\frac{1}{L_{1}} H_{3} \frac{\partial H_{3}}{\partial z_{1}}\right), \\
& F\left(\varphi, r_{1}, z_{1}\right) \equiv\left(1+2 \frac{\beta_{o}}{\alpha_{o}}\right)\left(\frac{\partial X_{1}}{\partial \varphi}+\frac{1}{L_{1}^{2}} \frac{\partial Z_{1}}{\partial \varphi}\right)-\frac{\partial X_{1}}{\partial \varphi}-\frac{1}{L_{1}^{2}}\left(\frac{\partial X_{2}}{\partial r_{1}}+\frac{\partial X_{3}}{\partial z_{1}}\right)-\frac{\beta_{o}}{\alpha_{o}}\left(\frac{\partial X_{4}}{\partial r_{1}}+2 \frac{\partial X_{5}}{\partial r_{1}}\right), \\
& G\left(\varphi, r_{1}, z_{1}\right) \equiv\left(1+2 \frac{\beta_{o}}{\alpha_{o}}\right)\left(\frac{\partial X_{1}}{\partial z_{1}}+\frac{1}{L_{1}^{2}} \frac{\partial Z_{1}}{\partial z_{1}}\right)-\frac{1}{L_{1}^{2}} \frac{\partial Z_{1}}{\partial z_{1}}-\left(\frac{\partial Z_{2}}{\partial r_{1}}+\frac{\partial Z_{3}}{\partial \varphi}\right)-\frac{\beta_{o}}{\alpha_{o}}\left(\frac{\partial Z_{4}}{\partial r_{1}}+2 \frac{\partial Z_{5}}{\partial r_{1}}\right), \\
& \mathrm{X}_{1} \equiv\left(\frac{\partial \mathrm{v}_{1}^{(0)}}{\partial \mathrm{r}_{1}}\right)^{2}, \quad \mathrm{X}_{2} \equiv \frac{\partial \mathrm{v}_{3}^{(0)}}{\partial \mathrm{r}_{1}} \mathrm{Y}_{4}-2 \frac{\partial \mathrm{v}_{1}^{(0)}}{\partial \mathrm{r}_{1}} \frac{\partial \mathrm{v}_{3}^{(0)}}{\partial \mathrm{z}_{1}}, \quad \mathrm{X}_{3} \equiv \frac{\partial \mathrm{v}_{1}^{(0)}}{\partial \mathrm{r}_{1}} \frac{\partial \mathrm{v}_{3}^{(0)}}{\partial \mathrm{r}_{1}} \\
& X_{4} \equiv \frac{\partial}{\partial r_{1}}\left(v_{1}^{(0)} \frac{\partial_{1}^{(0)}}{\partial \varphi}+v_{2}^{(0)} \frac{\partial_{1}^{(0)}}{\partial r_{1}}+\frac{1}{L_{1}^{2}} v_{3}^{(0)} \frac{\partial_{1}^{(0)}}{\partial z_{1}}\right), \quad X_{5} \equiv \frac{\partial_{1}^{(0)}}{\partial \phi} \frac{\partial_{1}^{(0)}}{\partial r_{1}}+\frac{1}{L_{1}^{2}} \frac{\partial_{3}^{(0)}}{\partial \varphi} \frac{\partial_{3}^{(0)}}{\partial r_{1}} \text {, } \\
& \mathrm{Y}_{1} \equiv \frac{\partial \mathrm{v}_{1}^{(0)}}{\partial \phi}, \quad \mathrm{Y}_{2} \equiv \frac{\partial \mathrm{v}_{2}^{(0)}}{\partial \mathrm{r}_{1}}, \quad \mathrm{Y}_{3} \equiv \frac{\partial \mathrm{v}_{3}^{(0)}}{\partial \mathrm{z}_{1}}, \quad Y_{4} \equiv \frac{\partial v_{3}^{(0)}}{\partial \varphi}+\frac{\partial v_{1}^{(0)}}{\partial \mathrm{z}_{1}}
\end{aligned}
$$




$$
\begin{aligned}
& \mathrm{Z}_{1} \equiv\left(\frac{\partial \mathrm{v}_{3}^{(0)}}{\partial \mathrm{r}_{1}}\right)^{2}, \quad Z_{2} \equiv \frac{\partial_{1}^{(0)}}{\partial r_{1}} Y_{4}-2 \frac{\partial_{3}^{(0)}}{\partial r_{1}} \frac{\partial v_{1}^{(0)}}{\partial \varphi}, \quad \mathrm{Z}_{3} \equiv \frac{\partial \mathrm{v}_{1}^{(0)}}{\partial \mathrm{r}_{1}} \frac{\partial \mathrm{v}_{3}^{(0)}}{\partial \mathrm{r}_{1}} \\
& \mathrm{Z}_{4} \equiv \frac{\partial}{\partial \mathrm{r}_{1}}\left(\mathrm{v}_{1}^{(0)} \frac{\partial \mathrm{v}_{3}^{(0)}}{\partial \phi}+\mathrm{v}_{2}^{(0)} \frac{\partial \mathrm{v}_{3}^{(0)}}{\partial \mathrm{r}_{1}}+\frac{1}{\mathrm{~L}_{1}^{2}} \mathrm{v}_{3}^{(0)} \frac{\partial \mathrm{v}_{3}^{(0)}}{\partial \mathrm{z}_{1}}\right), \quad \mathrm{Z}_{5} \equiv \frac{\partial \mathrm{v}_{1}^{(0)}}{\partial \mathrm{r}_{1}} \frac{\partial \mathrm{v}_{1}^{(0)}}{\partial \mathrm{z}_{1}}+\frac{1}{\mathrm{~L}_{1}^{2}} \frac{\partial \mathrm{v}_{3}^{(0)}}{\partial \mathrm{z}_{1}} \frac{\partial \mathrm{v}_{3}^{(0)}}{\partial \mathrm{r}_{1}}, \\
& h_{p 1}=\left[1-\lambda \cdot \cos \varphi+a_{\gamma} \cdot z_{1} \cdot \cos (\varphi)\right], \quad a_{\gamma}=\frac{L_{1}}{\psi} \tan (\gamma), \\
& 0 \leq r_{1} \leq h_{p 1}, 0 \leq \varphi<\varphi_{k},-1 \leq z_{1}<+1, s \equiv r_{1} / h_{p 1}, 0 \leq s \leq 1,0 \leq \mathrm{r}_{1} \leq \mathrm{r}_{2} \leq \mathrm{r}_{3} \leq \mathrm{h}_{\mathrm{c} 1}, \\
& \text { a } \quad-\text { misalignment factor, } \\
& r_{1}, z_{1} \quad-\text { dimensionless radial and longitudal coordinate, } \\
& \mathrm{q}_{1 \mathrm{c}}^{(0)} \quad-\text { dimensionless density of heat stream, } \\
& h_{p 1} \quad-\text { dimensionless height of lubrication gap, } \\
& h_{c 1} \quad-\text { dimensionless overall height of the lubrication gap, } \\
& \phi \quad-\text { peripheral coordinate, } \\
& \gamma \quad-\text { skew angle, } \\
& \lambda \quad-\text { angle of misalignment, } \\
& \chi \quad-\text { magnetic susceptibility coefficient, } \\
& \psi \quad-\text { dimensionless value of radial relative clearance, } \\
& \Omega_{1} \quad-\text { dimensionless heat supplied from outside sources to ferro-oil, } \\
& L_{1} \quad-\text { dimensionless length of bearing, } \\
& R_{f} \quad-\text { magnetic pressure number, } \\
& \eta_{1 B} \quad-\text { dimensionless dynamic viscosity depends on magnetic field induction, } \\
& \mathrm{p}_{1}^{(0)} \quad-\text { dimensionless hydrodynamic pressure, } \\
& \alpha_{0}, \beta_{0} \quad-\text { dimensional values of ferro-oil material coefficients, } \\
& \mathrm{v}_{1}, \mathrm{v}_{2}, \mathrm{v}_{3}-\text { dimensionless velocity vector components of ferro-oil, } \\
& H_{1}, H_{2}, H_{3} \quad \text { - dimensionless vector components of a magnetic field strength, } \\
& p_{10}^{(1)}, p_{11}^{(1)}, p_{1}^{(1)} \text { - dimensionless hydrodynamic pressure correction taking into account respectively: } \\
& \text { temperature influence on dynamic viscosity, effect of pressure on dynamic viscosity and influence } \\
& \text { of non-Newtonian properties. }
\end{aligned}
$$

\section{Results of modelling}

In order to determine the function of distribution of hydrodynamic pressure, the small parameter method has been used. This method consists in exchanging the wanted dimensionless quantities with convergent series related to small parameters [11, 13, 14]. As the small dimensionless parameters, the following values have been accepted. Deborah's number $\mathrm{De}_{\alpha}$ that is responsible for determining the impact of non-Newtonian ferro-oil properties on changes in flow and performance parameters. Dimensionless $Q_{\mathrm{Br}}$ factor describes the changes in viscosity on temperature. In turn, changes in dynamic viscosity under the influence of hydrodynamic pressure have been determined by changes in the dimensionless value of piezo-factor $\zeta_{p}$. The appointment of the small parameters and the appropriate designations has been taken as applied in the monography of A. Miszczak [13].

Table 1 below presents the determined and adopted values of the small parameters for particular concentrations of magnetic particles in ferro-oil.

In addition, the characteristic dimensional values of dynamic viscosity $\eta_{o}$ for $T=T_{o}=90^{\circ} \mathrm{C}$ 
and $p=p_{a t}$ as well as values of magnetic susceptibility coefficients of a ferro-oil have been determined experimentally [9] and their adopted values [2, 3, 8, 10] are shown in Tab. 2.

Tab. 1. The small parameters values adopted in the paper: $Q_{B r}, \zeta_{p}$ and De $\alpha$

\begin{tabular}{|l|c|c|c|c|}
\hline \multirow{2}{*}{$\begin{array}{c}\text { The small } \\
\text { parameters values }\end{array}$} & \multicolumn{4}{|c|}{ Magnetic particles concentration $n_{c s}$} \\
\cline { 2 - 5 } & $0 \%$ & $2 \%$ & $4 \%$ & $6 \%$ \\
\hline$Q_{\mathrm{Br}}$ & 0.044603 & 0.061210 & 0.083820 & 0.213011 \\
\hline$\zeta_{p}$ & 0.001579 & 0.002815 & 0.003834 & 0.008493 \\
\hline $\mathrm{De}_{\alpha}$ & 0.025856 & 0.020626 & 0.015396 & 0.006106 \\
\hline
\end{tabular}

Tab. 2. Values of viscosity coefficients and magnetic susceptibility coefficients adopted in the paper

\begin{tabular}{|l|c|c|c|c|}
\hline \multirow{2}{*}{$\begin{array}{c}\text { Values of the } \\
\text { parameters }\end{array}$} & \multicolumn{4}{|c|}{ Magnetic particles concentration $n_{c s}$} \\
\cline { 2 - 5 } & $0 \%$ & $2 \%$ & $4 \%$ & $6 \%$ \\
\hline$\eta_{o}^{\left({ }^{\circ}{ }^{\circ} \mathrm{C}\right)}[\mathrm{Pa} \cdot \mathrm{s}]$ & 0.01547 & 0.01939 & 0.02598 & 0.06550 \\
\hline$\chi[-]$ & 0 & 0.06007 & 0.08227 & 0.11764 \\
\hline$a_{B}\left[\mathrm{~T}^{-\delta 1 \mathrm{~B}}\right]$ & 0 & 0.57169 & 0.78382 & 1.09677 \\
\hline$\delta_{1 B}[-]$ & 1 & 0.24601 & 0.25433 & 0.21690 \\
\hline$a_{T}[-]$ & 0.93535 & 0.73721 & 0.72791 & 0.68873 \\
\hline$\delta_{T}\left[\mathrm{~K}^{-1}\right]$ & 0.04805 & 0.05261 & 0.05377 & 0.05419 \\
\hline$a_{p}[-]$ & 1.35221 & 1.60595 & 1.68489 & 1.75598 \\
\hline$\zeta\left[\mathrm{Pa}^{-1}\right]$ & $4.59 \cdot 10^{-8}$ & $6.53 \cdot 10^{-8}$ & $6.64 \cdot 10^{-8}$ & $5.83 \cdot 10^{-8}$ \\
\hline
\end{tabular}

There have been adopted the following dimensional and dimensionless quantities for all calculations of operational parameters: a low-speed bearing with an angular velocity of the journal $\omega=20 \mathrm{~s}^{-1}$ was assumed; the journal radius was $R=0.15 \mathrm{~m}$ and the dimensionless bearing length $L_{1}=1$; a constant dimensionless radial relative clearance value $\psi=0.003$ has been adopted; the ferro-oil thermal conduction coefficient was established as unchangeable and was equal $\kappa=0.15$; the material coefficients of a ferro-oil were respectively: $\alpha=0.000020$ and $\beta=-0.000010$; the value of the magnetic field intensity vector was assumed at the level ensuring full magnetic saturation of a ferro-oil $H_{o}=280000 \mathrm{~A} \cdot \mathrm{m}^{-1}$ [9]. In the calculations carried out, it was assumed that the bearing placement effect will not be taken into account in the model, hence the misalignment angle was $\gamma=0^{\circ}$.

Calculation of operating parameters was carried out for the assumed concentrations of magnetic particles $\mathrm{n}_{\mathrm{cs}}$ in ferro-oil of: $0 \%, 2 \%, 4 \%$ and $6 \%$, taking into account the relative eccentricity of the slide bearing $\lambda=0.6$.

There have been realized the calculations of hydrodynamic pressure distributions for cases of ferro-oil bearing lubrication taking into account the influence of external magnetic field and subsequent corrections of these parameters responsible for the effect of temperature changes and the effect of pressure changes on changes in dynamic viscosity of ferro-oil as well as corrections taking into account the viscoelastic properties of ferro-oil. Following figures, Fig. 1-4, show the results of distributions of a calculated hydrodynamic pressure in the form of four successive characteristics of basic values and abovementioned three corrections values. Designation (a) concerns results that take into account the Newtonian properties of ferro-oils subject to the influence of the external magnetic field; designations (b) refers to corrections of hydrodynamic pressure derived from the impact of temperature changes on the dynamic viscosity of ferro-oil, mark (c) means corrections from the impact of pressure changes on dynamic viscosity, mark (d) means corrections from non-Newtonian properties. 


\section{Conclusions}

Analysing particular cases of hydrodynamic pressure distributions and corrections of these distributions can be concluded that the use of ferro-oil instead of the base oil as a lubricant in the slide journal bearing results in a significant increase in the maximum pressure in the lubrication gap. This increase reaches $79 \%$ at the highest concentration of $6 \%$ of the value relative to the pressure calculated for the base oil. It should be noted that these changes result only from the action of magnetic members in the Reynolds equation.

The change in the maximum value of the hydrodynamic pressure correction associated with changes in viscosity from temperature is similar to the initial values for the base case of ferro-oil lubrication. The relative change in the minimum hydrodynamic pressure depends significantly on the concentration of magnetic particles in the ferro-oil. The largest change gradient applies to the base oil and low-concentration ferro-oils and decreases with the increase in the concentration of magnetic particles.

a)

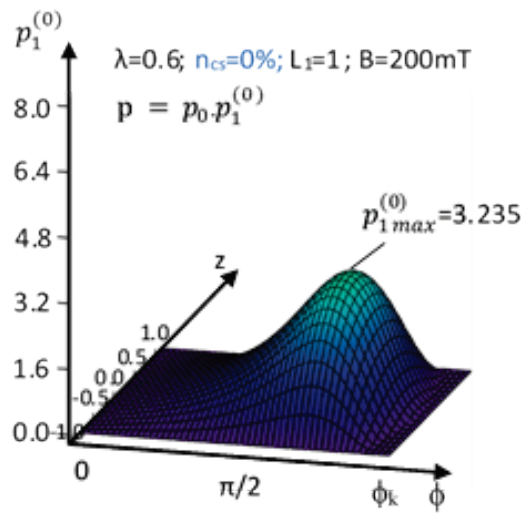

c)

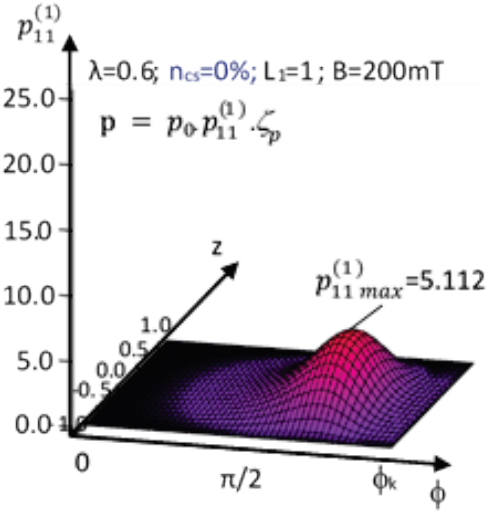

b)

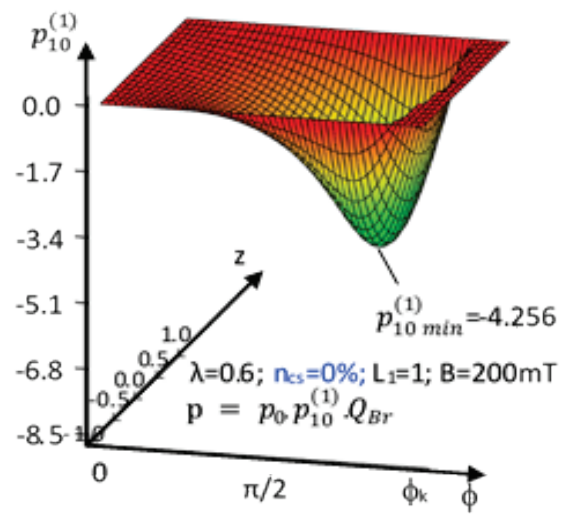

d)

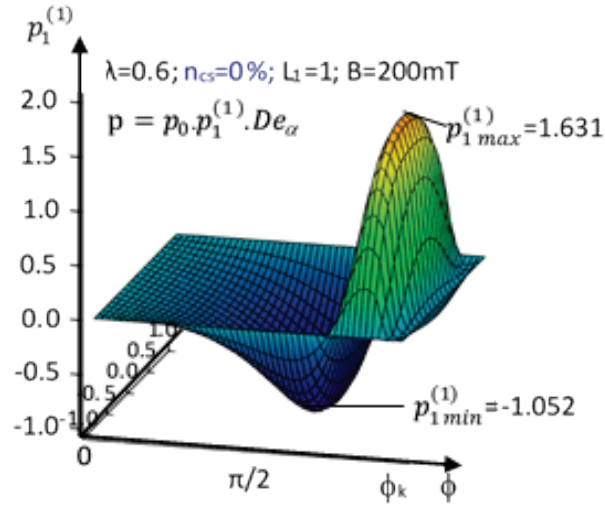

Fig. 1. The hydrodynamic pressure distribution (a) and three corrections of this pressure (b), (c) and (d) in the gap of the slide journal bearing lubricated with base oil for relative eccentricity $\lambda=0.6$

The change in the maximum value of the hydrodynamic pressure correction associated with changes in viscosity and pressure strongly depends on the lubrication conditions in the bearing. Despite the relatively high values of the relative change in the correction of the maximum hydrodynamic pressure, their absolute change achieves much lower values than the corrections related to temperature changes due to the much smaller value of the small parameter $\zeta_{p}$ compared to the $Q$ Br parameter.

Changes in hydrodynamic pressure corrections related to non-Newtonian properties of a lubricating ferro-oil bearing with the concentration of magnetic particles assume negligibly small values. In addition, the shape of the pressure correction distribution itself is almost unchanged in the aspect of changes in the concentration of magnetic particles in ferro-oil. 
a)

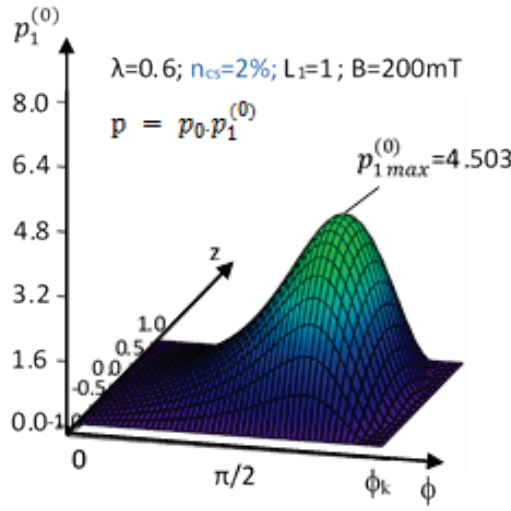

c)

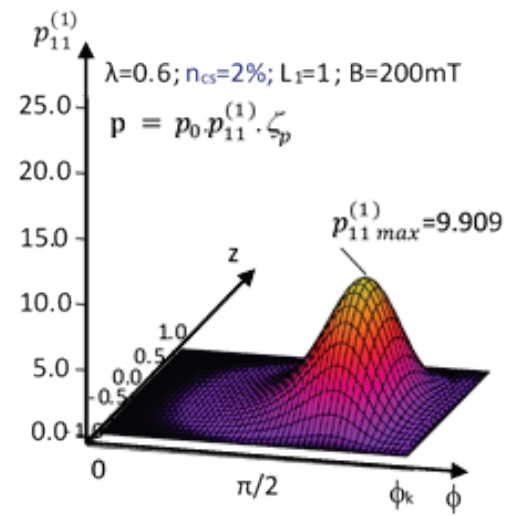

b)

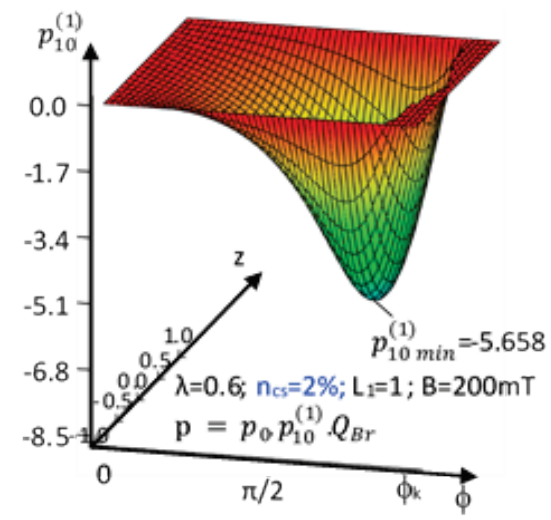

d)

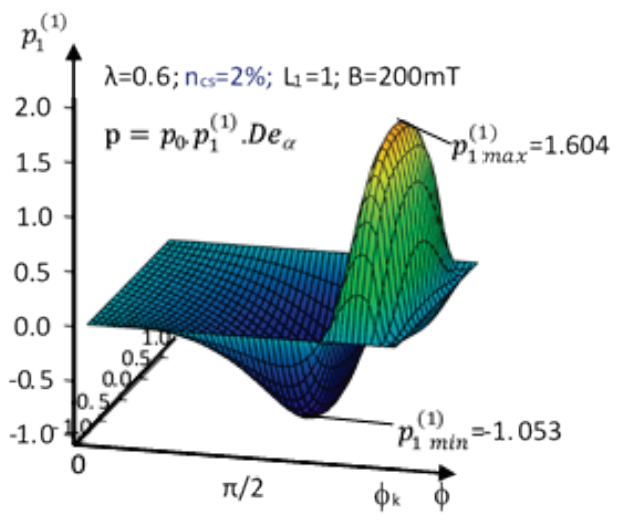

Fig. 2. The hydrodynamic pressure distribution (a) and three corrections of this pressure (b), (c) and (d) in the gap of the slide journal bearing lubricated with $2 \%$ ferro-oil for relative eccentricity $\lambda=0.6$

a)

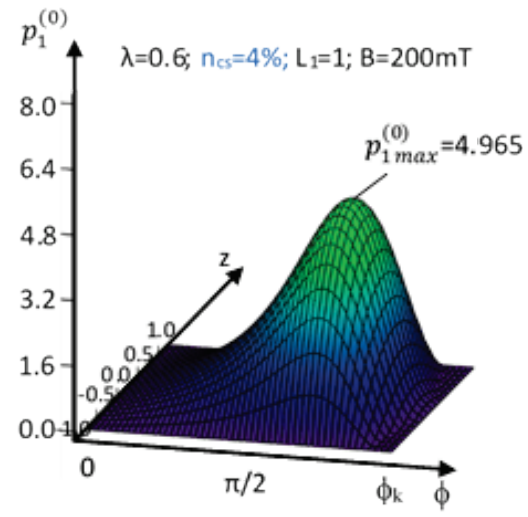

c)

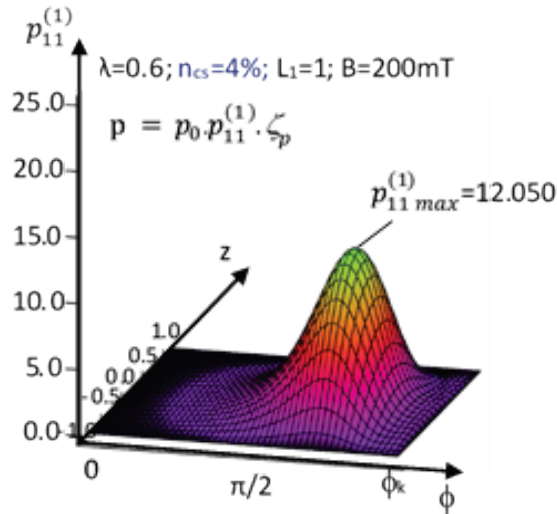

b)

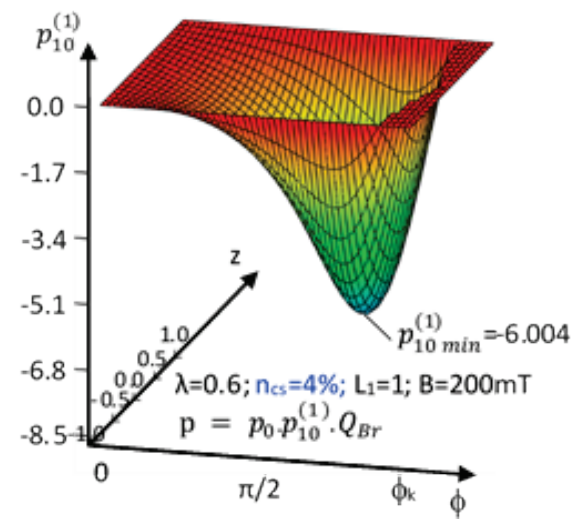

d)

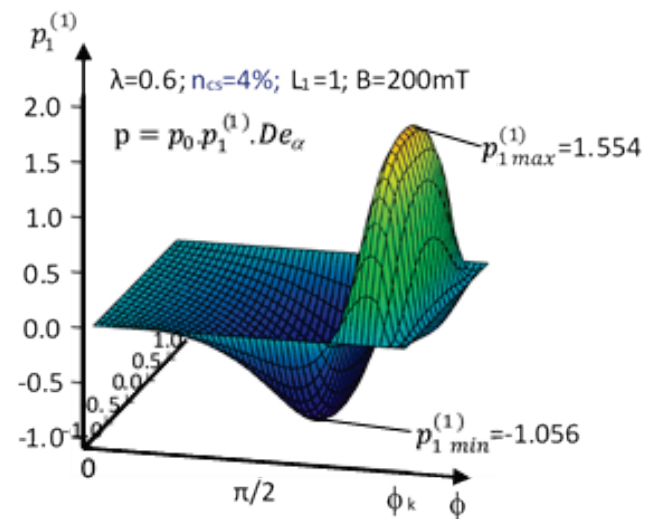

Fig. 3. The hydrodynamic pressure distribution (a) and three corrections of this pressure (b), (c) and (d) in the gap of the slide journal bearing lubricated with $4 \%$ ferro-oil for relative eccentricity $\lambda=0.6$ 
a)

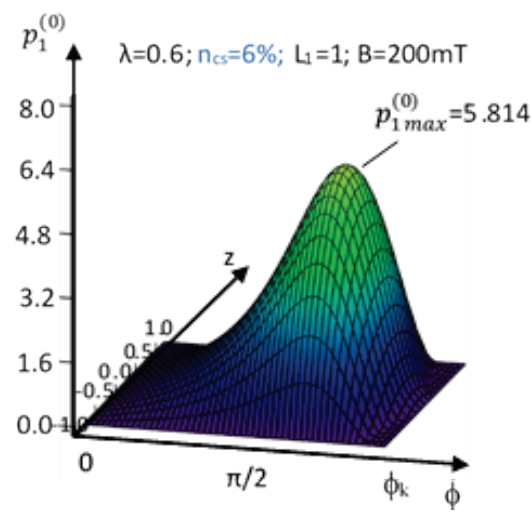

c)

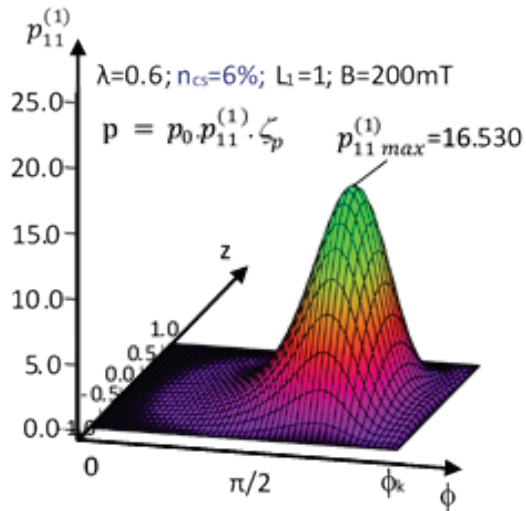

b)

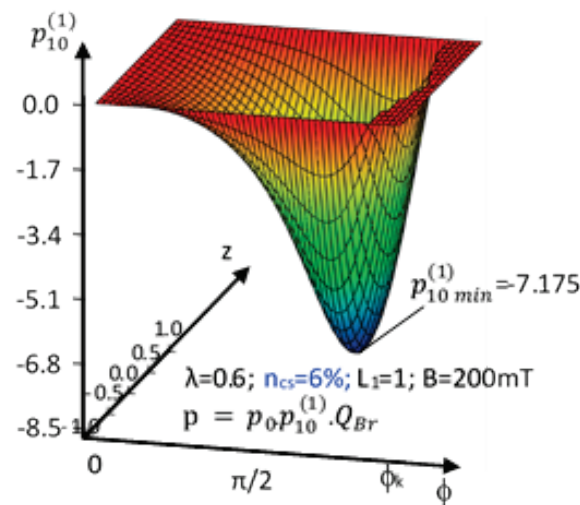

d)

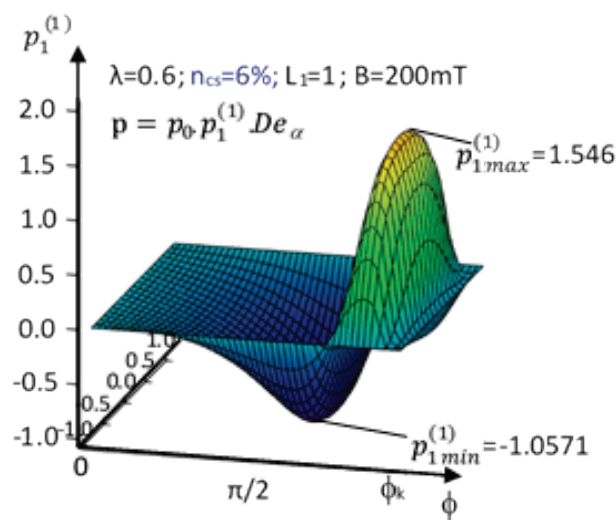

Fig. 4. The hydrodynamic pressure distribution (a) and three corrections of this pressure (b), (c) and (d) in the gap of the slide journal bearing lubricated with $6 \%$ ferro-oil for relative eccentricity $\lambda=0.6$

\section{References}

[1] Dudziewicz, J., Podstawy elektromagnetyzmu, WNT, Warszawa 1972.

[2] Frycz, M., The ferro-oils viscosity dependent simultaneously on the temperature and magnetic oil particles concentration $\eta=\eta(T, \varphi)$ - part I, Journal of KONES. Powertrain and Transport, Vol. 23, pp. 113-120, 2016.

[3] Frycz, M., The research and modelling of dynamic viscosity of the ferro-oils with the different concentrations of magnetic particles in the aspect of pressure changes, Tribologia. Teoria i Praktyka, Vol. 2, pp. 39-48, 2017.

[4] Frycz, M., Effect of Temperature and deformation rate on the dynamic viscosity of ferrofluid, Solid State Phenomena, Vol. 199, pp. 137-142, 2013.

[5] Frycz, M., Horak, W., Effect of the concentration of the magnetic particles in the ferrooil on its dynamic's viscosity changes in an external magnetic field, Solid State Phenomena, Vol. 220-221, pp. 324-327, 2015.

[6] Frycz, M., Miszczak, A., Influence of magnetic particles concentration in ferro-oils on values of friction force and coefficient of friction of slide journal bearings, Journal of KONES Powertrain and Transport, Vol. 24, pp. 143-150, 2017.

[7] Frycz, M., Miszczak, A., Longitudinal magnetic field in the journal sliding bearing gap, Tribologia. Teoria i Praktyka, Nr 6 (240), pp. 77-85, 2011.

[8] Frycz, M., Wplyw stężenia czastek magnetycznych $w$ ferrooleju na parametry przepływowe $i$ eksploatacyjne poprzecznych łożysk ślizgowych, Wydział Mechaniczny UMG, 2018.

[9] Frycz, M., Impact of temperature on magnetic susceptibility coefficient $\chi$ of ferro-oils with different concentration of magnetic particles, Tribologia, Teoria i Praktyka, Vol. 5, pp. 21-30, 2016. 
[10] Frycz, M., Czaban, A., Models of viscosity characteristics $\eta=\eta(B)$ of ferro-oil with different concentration of magnetic particles in the presence of external magnetic field, Journal of KONES. Powertrain and Transport, Vol. 21, No. 4, pp. 119-126, 2014.

[11] Kalinin, A. I., Lavrinovich, L. I., Application of the small parameter method to the singularly perturbed linear-quadratic optimal control problem, Automation and Remote Control, Vol. 77, pp. 751-763, 2016.

[12] Miszczak, A., Frycz, M., Wpływ stężenia cząstek magnetycznych w ferrooleju na wartość sity nośnej w poprzecznym łożysku ślizgowym przy uwzględnieniu zmian lepkości od pola magnetycznego, ciśnienia i temperatury, Logistyka - Nauka, Vol. 6, 2014.

[13] Miszczak, A., Analiza hydrodynamicznego smarowania ferrociecza poprzecznych tożysk ślizgowych, Monografia. Fundacja Rozwoju Akademii Morskiej, Gdynia 2006.

[14] Pawlak, W., Practical methods of dynamic objects identification Part I. Small perturbations method, Prace Instytutu Lotnictwa, Vol. 170-171, pp. 57-64, 1998.

[15] Walicka, A., Rheology of fluids in mechanical engineering, Oficyna Wydawnicza Uniwersytetu Zielonogórskiego, Zielona Góra 2017.

[16] Wierzcholski, K., Mathematical methods of hydrodynamic theory of lubrication, Politechnika Szczecińska, Monografia, Nr 511, Szczecin 1993.

[17] Wierzcholski, K., Miszczak, A., Równania hydrodynamicznej teorii smarowania ciecza o cechach modelu Rivlina Ericksena, Zagadnienia Eksploatacji Maszyn, Vol. 31, Z. 3 (106), pp. 7-18, 1996.

Manuscript received 27 September 2019; approved for printing 06 December 2019 